\title{
Purificación parcial y caracterización de una sustancia antimicrobiana producida por Alteromonas sp. de origen marino
}

\section{Partial purification and characterization of an antimicrobial substance produced by a marine Alteromonas sp.}

\author{
Jorge León ${ }^{1}$, Guillermina Tapia ${ }^{2}$ y Rita Avalos ${ }^{1}$
}

Presentado: 07/09/2005

Aceptado: $\quad$ 09/01/2006

\section{Resumen}

Un miembro del género Alteromonas sp. (cepa N22.C), aislado del neuston marino y productor de sustancias que inhiben el crecimiento de ictiopatógenos fue caracterizado fenotípicamente mediante pruebas morfológicas, fisiológicas y bioquímicas convencionales. Para determinar la naturaleza química de la sustancia inhibitoria, extractos crudos de sobrenadantes de cultivos fueron precipitados con concentraciones crecientes de Sulfato de Amonio hasta el $70 \%$ y filtrados a través de columnas de Sephadex G-25. Ensayos con Dodecil Sulfato de Sodio-electroforesis en Geles de Poliacrilamida (SDSPAGE) revelaron que la sustancia antimicrobiana es un compuesto proteináceo con una masa molecular de aproximadamente $34000 \mathrm{Da}$, que carece de residuos de azúcares asociados. Otros ensayos realizados con extractos crudos y fracciones semipurificadas de la cepa de Alteromonas sp. N22.C mostraron un amplio espectro de actividad antibiótica contra cepas de bacterias patógenas de peces, moluscos y crustáceos.

Palabras claves: bacterias marinas, actividad inhibitoria, sustancia extracelular, Alteromonas, antibiosis.

\section{Abstract}

A member of the genus Alteromonas sp. (strain N22.C) isolated from marine neuston and substance-producer which inhibit growth of ichthyopathogenics was characterized phenotipically by means of morphological, physiological and biochemical conventional tests. To determine the chemical nature of the inhibitory substance, raw extracts of supernatans from cultured strains were precipitated with increasing concentrations of Ammonium Sulphate up to $70 \%$ and filtered through columns of Sephadex G-25. Assays by Sodium Dodecyl Sulfate-Polyacrylamide Gel Electrophoresis (SDS-PAGE) revealed that the antimicrobial substance is a proteinaceous compound with a molecular mass of approximately $34000 \mathrm{Da}$, which lacks sugar associated residues of it. Other assays made with raw semipurified fractions extracts of Alteromonas sp N22.C show the wide spectrum of antibiotic activity against pathogenic bacterial strains of fish, mollusks and crustaceans.

Keywords: marine bacteria, inhibitory substances, extracellular substance, Alteromonas, antibiosis. \section{Introducción}

Los microorganismos marinos han recibido particular atención en las últimas décadas como fuentes de nuevos recursos biomédicos (Kelecom, 2002). Asimismo, diversos metabolitos secundarios y nuevas substancias de naturaleza química única y de origen microbiano presentan aplicaciones promisorias en el ámbito de la biotecnología marina (Fenical

\footnotetext{
${ }^{1}$ Laboratorio de Microbiología Ambiental y Biotecnología, Facultad de Ciencias Biológicas, Universidad Nacional Mayor de San Marcos, Apartado 110058, Lima 11, Perú. E-mail Jorge León: jleonq@ unmsm.edu.pe

${ }^{2}$ Laboratorio de Bioquímica, Facultad de Ciencias Básicas - Carrera de Bioquímica-Universidad Católica de Valparaíso, Chile.
}

\& Jensen, 1993; Bradley, 1995; BioScience, 1996). Entre las numerosas substancias con principios bioactivos de origen marino destacan los antibióticos producidos en forma natural por microorganismos (Gatesoupe, 1999). Estos podrían ser de gran utilidad en el control de enfermedades en la acuicultura (Abraham, 2004) en particular en patologías de peces, moluscos y crustáceos (Austin et al. 1995; Gatesoupe, 1999).

La producción de substancias antibióticas por bacterias aisladas del ecosistema marino ha sido largamente documentada (Kelecom, 2002). Uno de los primeros reportes que marcó un hito en el estudio de bacterias marinas productoras de substancias antibióticas fue el 
de Rosenfeld \& ZoBell (1947), quienes sugirieron que el ambiente marino debería ser considerado como una fuente potencial de antibióticos naturales. Posteriormente se ha evaluado ese efecto frente a diversas bacterias patógenas de humanos (Jayanth et al., 2002) de peces y moluscos (Dopazo et al., 1988; Lodeiros et al., 1988; León, 1996; Riquelme et al., 1996) y en la actualidad se ha llegado a conocer incluso el efecto bactericida que tienen frente a cepas resistentes a antibióticos como Staphylococcus aureus meticilino-resistentes (Isnansetyo \& Kamei, 2003).

El desarrollo de métodos de extracción y purificación de substancias inhibitorias activas, ha permitido conocer su naturaleza química, encontrándose compuestos proteináceos (Riquelme et al. (1996), glicoproteinas termolábiles Barja et al. (1986) y lipopolisacáridos (Gauthier, 1970), todos con un amplio espectro de actividad inhibitoria.

En el presente trabajo se describen características fenotípicas de una cepa de Alteromonas productora de una sustancia antibacteriana. Asimismo, se describen aspectos de la extracción, purificación y caracterización bioquímica de la sustancia inhibitoria, y la determinación de capacidades antibióticas de extractos crudos y semipurificados.

\section{Material y métodos}

\section{Aislamiento y caracterización bacteriana}

La cepa de Alteromonas marina N22.C fue aislada de la película superficial del agua (interfase agua-aire) recolectada en las pozas intermareales de Montemar - Instituto de Oceanología de la Universidad de Valparaíso, Chile (32²7'S, $71^{\circ} 33$ W). El aislamiento bacteriano se realizó en Agar Marino 2216 (Difco) con incubaciones de $20^{\circ} \mathrm{C}$ por 6 días. Las características morfológicas y bioquímicas de las cepas fueron determinadas según los procedimientos descritos en por Baumann \& Baumann (1984) en el Bergey's Manual of Systematic Bacteriology. Complementariamente se hicieron observaciones al microscopio electrónico de transmisión(Siemens, Elmiskop Tipo IA).

\section{Condiciones de cultivo y extracción de la substancia inhibitoria}

El medio de cultivo para la caracterización de la substancia antibiótica producida por la cepa descrita se preparó según la formulación de Gauthier (1976), modificada por el autor en la adición de $0,1 \%$ de glucosa en lugar de 5\% de almidón.

Se utilizó el caldo marino de ZoBell (CMZ), conteniendo los siguientes componentes: proteosa-peptona $0,5 \%$ (p/v) (Oxoid), extracto de levadura $0,1 \%$ (p/v) (Oxoid), FePO4 0,01\% $(\mathrm{p} / \mathrm{v})$, glucosa $0,1 \%(\mathrm{p} / \mathrm{v})$, todo diluido con una mezcla de agua de mar «envejecida» y agua destilada (3:1), y con un pH 7,6. La cepa N22.C se inoculó a partir de un pre-cultivo de 24 h, en 200 $\mathrm{ml}$ de $\mathrm{CMZ}$ distribuidos en Erlenmeyer de 500 $\mathrm{mL}$. Los cultivos se incubaron a $20^{\circ} \mathrm{C}$ con agitación constante de 60 golpes por minuto hasta alcanzar la fase estacionaria a los 4 días.

La extracción del producto antimicrobiano se realizó según el método de Barja et al. (1989), con modificaciones de los autores. El proceso de extracción se realizó a $4{ }^{\circ} \mathrm{C}$. El cultivo fue centrifugado a $8000 \mathrm{xg}$ por 15 minutos en una centrífuga refrigerada (Sorvall RC-5B). El sobrenadante colectado fue sometido a precipitaciones fraccionadas de proteínas según Keen (1966) con Sulfato de Amonio a concentraciones saturantes hasta $70 \%$. Luego de 16 h, la muestra se centrifugó a 13000 xg por 20 minutos. El precipitado fue disuelto en agua destilada estéril, luego liofilizada y conservado a la temperatura de $-20{ }^{\circ} \mathrm{C}$ hasta su posterior análisis. La muestra así obtenida fue considerada como «extracto crudo del sobrenadante» (ECS).

Con la finalidad de determinar la posible localización intracelular de la sustancia antibacteriana, se realizaron pruebas complementarias de actividad inhibitoria utilizando el pellet celular, según Barja (1989).

Los «extractos crudos» intra y extracelulares obtenidos fueron probados para determinar su actividad inhibitoria frente a Staphylococcus aureus ATCC 11632. 


\section{Filtración en columnas de gel de Sephadex}

La filtración en gel se realizó en columnas de Sephadex G-25 (2,2 por $25 \mathrm{~cm}$ ) equilibrada con tampón Tris- $\mathrm{HCl} 50 \mathrm{mM}(\mathrm{pH} 8,1)$ y $0,1 \mathrm{M}$ de $\mathrm{NaCl}$, con un flujo de $60 \mathrm{~mL} / \mathrm{h}$. El Azul Dextrano fue utilizado para determinar el volumen vacío de la columna y la homogeneidad del empaque de gel. Para el proceso de filtración, 0,5 g de ECS liofilizado se disolvió en $2 \mathrm{~mL}$ de agua destilada para luego aplicar $1 \mathrm{~mL}$ a la columna cromatográfica. Las fracciones colectadas $(1 \mathrm{~mL})$ fueron determinadas por su absorbancia a $280 \mathrm{~nm}$ (Shimadzu UV-150-02) y su actividad inhibitoria frente a $S$. aureus ATCC 11632. Las fracciones activas de los eluídos fueron juntadas $(5,0 \mathrm{~mL})$, luego liofilizadas y mantenidas a $-20^{\circ} \mathrm{C}$. Estas muestras fueron consideradas como substancias semipurificadas (SP).

\section{Determinación de la concentración de proteínas}

La concentración de proteínas en las muestras activas fue estimada según Brown et al. (1989), por el método del ácido bicinconínico (BCA). Para la construcción de la curva patrón se utilizó una solución estándar de 1,0 mg/ml de Seroalbúmina Bovina (BSA). La lectura de la absorbancia se realizó a 562 nm (A562).

\section{Ensayos de actividad inhibitoria}

La actividad inhibitoria de las fracciones obtenidas durante la extracción y purificación fue ensayada por dos métodos adaptados para bacterias marinas: el método de difusión en «pocillos» (Vignolo et al., 1993) y el método de difusión directa en placas (Naclerio et al., 1993). En ambos casos, se usó $S$. aureus ATCC 11632 y Vibrio anguillarum NCMB 2133 como cepas testigo y Tripticasa Soya Agar (TSA) como medio de siembra.

El método en «pocillos» se empleó para ensayos con ECS. El medio TSA fue cubierto con una suspensión del cultivo testigo $(10 \mu \mathrm{L})$ en $3 \mathrm{~mL}$ del medio semisólido. Luego de 30 minutos de difusión se prepararon pocillos de
$5 \mathrm{~mm}$ de diámetro y se inocularon $30 \mu \mathrm{L}$ de la muestra en cada pocillo. Las placas fueron incubadas a $30{ }^{\circ} \mathrm{C}$ por $24 \mathrm{~h}$ y luego evaluadas los halos de inhibición. Para las muestras semipurificadas (SP) se empleó el método de difusión directa según Naclerio et al. (1993). Las cepas testigo fueron sembradas de manera similar al anterior, pero la inoculación de las muestras $(10 \mu \mathrm{L})$ se hizo directamente sobre el cultivo después de la difusión de la segunda capa por 30 minutos.

\section{Preparación de geles y condiciones de electroforesis}

Los reactivos utilizados para electroforesis fueron de grado analítico Sigma. Todas las electroforesis se llevaron a cabo en geles discontinuos de Poliacrilamida-Dodecil Sulfato Sódico (PAGE-SDS), siguiendo la metodología de Laemmli (1970). La composición final de los geles fue de $3 \%$ de acrilamida y $0,08 \%$ de bis-acrilamida en tampón Tris- $\mathrm{HCl} 0,25 \mathrm{M}$; pH 6,8 para el gel concentrador y $12,5 \%$ de acrilamida y $0,22 \%$ de bis-acrilamida en tampón Tris- $\mathrm{HCl} 1,5 \mathrm{M}$; pH 8,0 para el gel separador. La polimerización se realizó con TEMED (N,N,N',N'-tetrametil-etilendiamina) al $0,4 \%$ (gel concentrador) y al $0,03 \%$ (gel separador) y persulfato amónico al $0,02 \%$ como agente catalizador. El tampón de corrida fue Tris-Glicina-SDS, pH 8,3. Muestras de SP reconstituidas en agua destilada estéril fueron cargadas sobre la placa de gel (14 x 16 $\mathrm{cm}$ ) en volúmenes de $50 \mu \mathrm{L}$ a cada carril. El proceso se desarrolló a una corriente constante de $30 \mathrm{~mA}$. Se utilizaron como marcadores (Kit MW-SDS-200, Sigma) las siguientes proteínas: miosina 205000 daltons (Da), $\beta$ galactosidasa $116000 \mathrm{Da}$, fosforilasa B 97400 Da, albúmina bovina 66000 Da, ovoalbúmina 45000 Da y anhidrasa carbónica 29000 Da.

\section{Tinción de proteínas}

Para la observación del perfil proteico se utilizó la tinción de nitrato de plata según Sambrook et al. (1989) y ocasionalmente la tinción de Azul de Coomassie. Las soluciones para las tinciones se prepararon de acuerdo a 
especificaciones, empleando reactivos de grado analítico. El fijado se realizó en papel celofán transparente, previamente humedecidos en una solución acuosa de glicerol al 5\%, dejando secar a temperatura ambiente.

\section{Tinción de Glicoproteínas}

Para detectar posibles azúcares asociados a la proteína inhibitoria se utilizó un sistema comercial adaptado para PAGE-SDS (Glicoprotein Detection Kit, Sigma) (tinción del ácido Periódico-Schiff-PAS para glicoproteínas). La presencia de estas moléculas se visualiza como bandas de color magenta con un fondo incoloro o rosado débil. Como marcador de glicoproteínas se utilizó peroxidasa de rábano (40000 Da). Para la tinción de glicoproteínas se siguieron las instrucciones del catálogo indicadas por el fabricante.

\section{Ensayo directo de actividad antimicrobiana en PAGE-SDS.}

Para determinar la actividad antimicrobiana del perfil proteico en PAGE-SDS de la sustancia SP, se utilizó el ensayo por bioautografía. La corrida de electroforesis se realizó en las mismas condiciones que las anteriores, pero preparativa.

Muestras de la sustancia SP activas fueron colocadas en volúmenes de $100 \mu \mathrm{L}$ a dos carriles. Después de realizada la electroforesis (4 h a $50 \mathrm{~mA}$ ), el gel fue retirado y cortado asépticamente en dos partes iguales. Una parte fue sometida a tinción para proteínas, en tanto la otra fue procesada para ver la actividad antimicrobiana por el método de Bhunia et al. (1988). Para este último ensayo el gel fue fijado inmediatamente con la solución de isopropanol al $20 \%$ en Tris $\mathrm{HCl} 10 \mathrm{mM}(\mathrm{pH}$ $7,5)$ por $3 \mathrm{~h}$, y lavado con Tris- $\mathrm{HCl} 10 \mathrm{mM}(\mathrm{pH}$ $7,5)$ por $1,5 \mathrm{~h}$. Luego el gel fue colocado sobre una placa conteniendo el medio TSA previamente inoculada con S. aureus ATCC 11632. La actividad de la substancia inhibitoria fue evidenciada por zonas de inhibición de crecimiento.

\section{Espectro inhibitorio de la substancia semipurificada (SP)}

El espectro de actividad antimicrobiana de la substancia semipurificada (SP) de Alteromonas
N22.C se realizó frente a una colección de cepas ictiopatógenas. El método empleado para esta prueba, fue el de difusión directa en placas de cultivo descrita anteriormente.

\section{Resultados}

\section{Características fenotípicas del cultivo}

La cepa N22.C de Alteromonas se observó como bacilos ligeramente rectos y con extremos redondeados, móviles por flagelos,

Tabla 1. Características fenotípicas de Alteromonassp. cepa N22.C aislada de las pozas intermareales de Montemar, Valparaíso, Chile.

\begin{tabular}{|c|c|c|}
\hline \multicolumn{2}{|l|}{ Caracteres } & a N22C \\
\hline \multicolumn{2}{|l|}{ Gram } & - \\
\hline \multicolumn{2}{|l|}{ Oxidasa } & + \\
\hline \multicolumn{2}{|l|}{ Catalasa } & + \\
\hline \multicolumn{2}{|c|}{ Luminiscencia } & - \\
\hline \multicolumn{2}{|c|}{ Pigmento } & - \\
\hline \multicolumn{2}{|c|}{ Presencia de Polihidroxibutirato (PHB) } & - \\
\hline \multicolumn{2}{|l|}{ Motilidad } & + \\
\hline \multicolumn{2}{|c|}{ Posición de flagelos } & Polar \\
\hline \multicolumn{2}{|c|}{ Metabolismo OF (Glucosa) } & $\mathrm{O}$ \\
\hline \multirow{2}{*}{\multicolumn{2}{|c|}{ Reducción de $\mathrm{NO}_{3} \mathrm{aNO}_{2}$}} & - \\
\hline & Hidróslisis de: Gelatina & + \\
\hline \multicolumn{2}{|c|}{ Caseína } & + \\
\hline \multicolumn{2}{|r|}{ Celulosa } & - \\
\hline \multirow{2}{*}{\multicolumn{2}{|c|}{ Almidón }} & + \\
\hline & & - \\
\hline \multirow{2}{*}{\multicolumn{2}{|c|}{ Alginato }} & - \\
\hline \multirow{2}{*}{\multicolumn{2}{|c|}{ Tween-80 }} & + \\
\hline & & + \\
\hline \multicolumn{2}{|r|}{ DNA } & + \\
\hline \multicolumn{2}{|r|}{ Urea } & - \\
\hline \multicolumn{2}{|c|}{ Requerimiento de agua de mar. } & si \\
\hline \multicolumn{2}{|c|}{ Requerimiento de sodio $\left(\mathrm{Na}^{+}\right)$} & si \\
\hline \multicolumn{2}{|c|}{ Crecim. $\mathrm{NaCl} 0 \%$} & - \\
\hline \multicolumn{2}{|r|}{$3 \%$} & + \\
\hline \multicolumn{2}{|r|}{$5 \%$} & + \\
\hline \multicolumn{2}{|r|}{$7 \%$} & + \\
\hline & $10 \%$ & $(+)$ \\
\hline \multirow[t]{4}{*}{ Crecim. a } & $8^{\circ} \mathrm{C}$ & - \\
\hline & $28^{\circ} \mathrm{C}$ & + \\
\hline & $35^{\circ} \mathrm{C}$ & + \\
\hline & $42^{\circ} \mathrm{C}$ & - \\
\hline \multicolumn{2}{|c|}{ Sensibilidad a O/ 129} & $\mathrm{R}$ \\
\hline \multicolumn{2}{|c|}{ Crecim. Mc Conkey } & NC \\
\hline Crecim. en & TCBS & NC \\
\hline Produc. Inc & $\mathrm{dol} / \mathrm{H}_{2} \mathrm{~S}$ & $-1-$ \\
\hline A naerobio & facultativo & - \\
\hline
\end{tabular}

+, reacción positiva; - , reacción negativa; ( ), reacción débil; O, oxidativo; R, resistente; $\mathrm{NC}$, no crecimiento. 


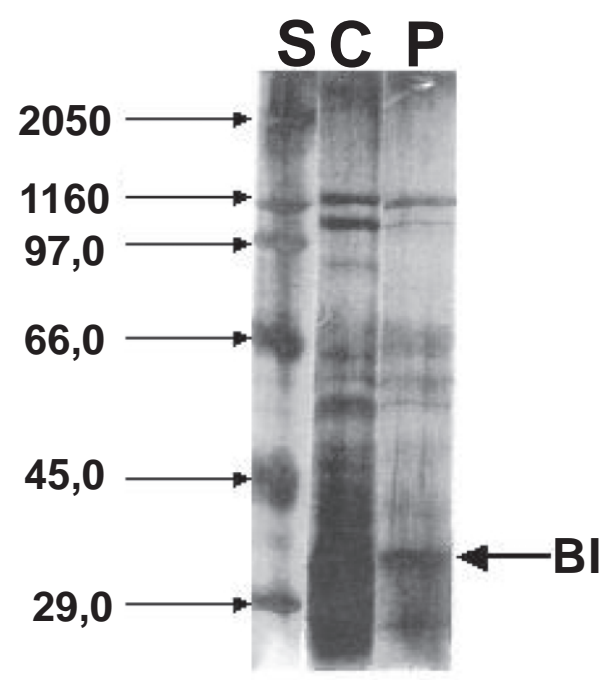

Figura 2. Electroforesis en gel de poliacrilamida - SDS de la sustancia inhibitoria (SI) de Alteromonas cepa N22.C, con tinción de plata. Carril C, extracto crudo del sobrenadante; carril P, SI semipurificada (eluidos activos después del filtrado por Sephadex G-25); carril S, estándar de pesos moleculares (MW-SDS-200, Sigma), 205000; 116000; 97000; 66000; 45000 у 29000 daltons (Da). La flecha (BI) indica la banda de proteína(s) involucrada(s) en las pruebas de inhibición.

de una banda cuya masa molecular oscila entre 45000 y 29000 fue persistente en todas las corridas electroforéticas, (Figura 3). Esta fracción de proteínas cuya masa molecular fue estimada entre $34000 \pm 4000$ Da se denominó «banda I» $(\mathrm{BI})$.

Las pruebas efectuadas mediante el ensayo directo de actividad antimicrobiana en PAGE-SDS, conducentes a determinar la actividad de las bandas proteicas de la sustancia SP, revelaron una zona de fuerte inhibición a la altura de la banda BI (cepa testigo $S$. aureus ATCC 11632) (Figura 4).

Otros ensayos en PAGE-SDS conducentes a la determinación de la presencia de azúcares unidos a las proteínas inhibitorias mostraron ausencia de dichas moléculas (Figura 5). En consecuencia la sustancia inhibitoria producida por Alteromonas N22.C fue catalogada simplemente como de naturaleza proteinacea. La con- centración de proteínas totales de la sustancia SP aplicadas a cada carril de PAGE-SDS, fue estimada en $170 \mathrm{mg} / \mathrm{mL}$.

\section{Espectro de actividad antimicrobiana de la substancia SP}

La sustancia semipurificada (SP) de Alteromonas N22.C, presentó actividades inhibitorias de amplio rango contra bacterias patógenas de peces y moluscos. Las cepas testigo ensayadas han resultado ser sensibles a la sustancia SP cuando éstas fueron inoculadas con $15 \mathrm{~mL}$ de muestra sobre la superficie de los cultivos en placa. Esta sensibilidad se muestra en la Tabla 3. El patógeno de mayor sensibilidad resultó ser Vibrio ordalii NCMB 2167, cuyo halo de inhibición logró superar $18 \mathrm{~mm}$ de diámetro. Otras cepas sensibles a la acción inhibitoria fueron $V$. anguillarum RP-13 (14 $\mathrm{mm}), \quad$. alginolyticus A32 (13 $\mathrm{mm})$, Pseudomonas aeruginosa (14 $\mathrm{mm}) \mathrm{y}$

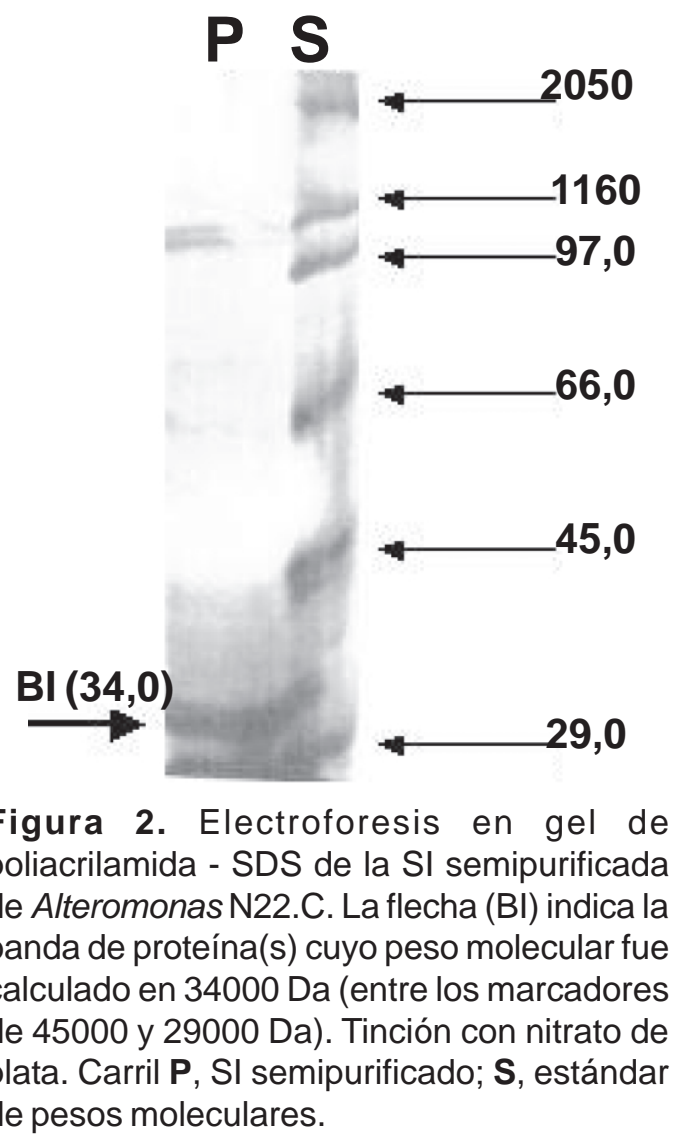



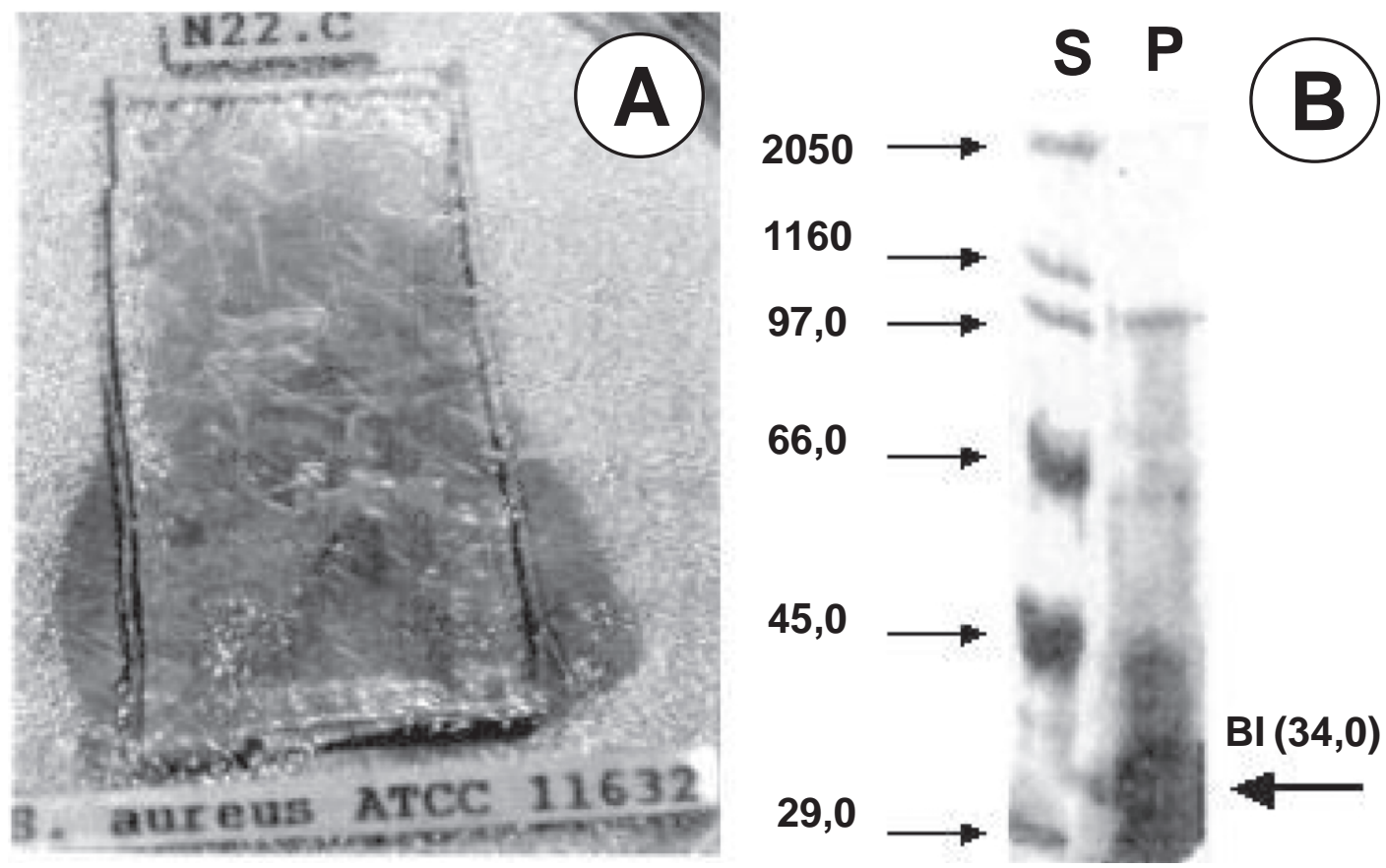

Figura 3 Ensayo directo de la actividad inhibitoria en PAGE - SDS de la sustancia SP de Alteromonas marina cepa N22.C. (A), porción del gel colocado sobre el cultivo de la cepa testigo (descrito en material y métodos); (B), porción del gel con tinción de plata. La flecha (BI) indica la banda de proteína(s) involucradas en el halo de inhibición mostrada en (A). S, estándar de pesos moleculares; P, sustancia semipurificada (SP).

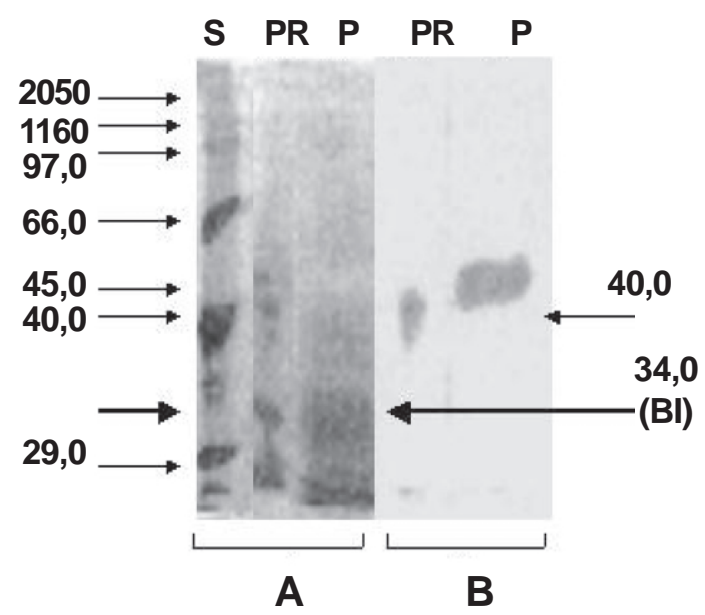

Figura 4. PAGE - SDS de la sustancia semipurificada (SP) de Alteromonas N22.C conducentes a descartar la presencia de azúcares asociados a las proteínas inhibitorias. (A), con tinción de plata para proteínas y (B), con tinción del ácido Periódico-Schiff (PAS) para glicoproteínas. Carril PR, peroxidasa de rábano, PM 40000 Da (control); P, SI semipurificado; S, estándar de pesos moleculares.
Tabla 3. Espectro de actividad inhibitoria de la sustancia semipurificada (SP) de Alteromonas marina cepa N22.C frente a bacterias ictiopatógenas.

\begin{tabular}{lc}
\hline Cepas ictiopatógenas & SP N22.C \\
\hline Vibrio tubiashii FX1 & $+($ a) \\
Vibrio anguillarum ATCC 19264 & ++ \\
Vibrio anguillarum N CMB 2133 & ++ \\
Vibrio anguillarum RP-13 & ++ \\
Vibrio anguillarum 775 & ++ \\
Vibrio ordalii N CMB 2167 & ++ \\
Vibrio ordalii 84/ 2559 & ++ \\
Vibrio damsela ATCC 33539 & + \\
Vibrio al ginolyticus A 32 & ++ \\
A eromonas hydrophila B-35 & ++ \\
A eromonas salmonicida 67.79 & ++ \\
A eromonas sobria P-281 & + \\
Pseudomonas aeruginosa ATCC 27853 & ++ \\
Y ersinia ruckeri PP-31 & ++ \\
Staphylococcus aureus ATCC 11632(b) & ++ \\
\hline
\end{tabular}

(a):,$+<8 \mathrm{~mm}$ zona de inhibición;,$++ 8-12 \mathrm{~mm}$ zona de inhibición; +++, 12-16 mm zona de inhibición; ,$++++>16 \mathrm{~mm}$ zona de inhibición.

(b): cepa control. 
Aeromonas hydrophila B-35 (13 mm). Entre las cepas menos sensibles resultaron Aeromonas sobria P-281 $(<8 \mathrm{~mm})$ y $V$. damsela ATCC 33539 (8 mm).

\section{Discusión}

Estudios de purificación y caracterización de las substancias inhibidoras producidas por bacterias marinas, demuestran que estas pueden ser de naturaleza molecular variable. El análisis detallado de las estructuras químicas de estas sustancias ha dado como resultados compuestos tanto de alto como de bajo peso molecular; sin embargo, en muchos casos se trata de moléculas únicas halogenadas propias de ambientes marinos. Las primeras substancias purificadas por Burkholder et al. (1966) y Andersen et al. (1974) fueron compuestos bromopirrólicos de bajo peso molecular y de espectro antimicrobiano variable. Estas substancias fueron consideradas de localización intracelular. Por su parte, Dogget (1968), purificó de una cepa de Vibrio un compuesto anti-Pseudomonas de alto peso molecular; mientras que Gauthier, (1970) caracterizó una sustancia inhibidora producida por Alteromonas como un lipopolisacárido, aunque mas tarde Bernard \& Petazzi (1977) lo consideraron como polisacárido. También Gauthier (1976a) y Gauthier \& Flatau, (1976) aislaron compuestos macromoleculares polianiónicos extracelulares de Alteromonas citrea, A. rubra y A. luteo-violaceus; de ésta última, además aislaron compuestos brominados de bajo peso molecular y de localización intracelular. Posteriormente, Lemos et al. (1985) y Dopazo et al. (1988) aislaron compuestos inhibitorios polianiónicos extracelulares de cepas de Alteromonas, con tamaños moleculares bajos (<2000 Da). Barja et al. (1989), purificaron y caracterizaron una sustancia antibacteriana producida por Alteromonas cepa $\mathrm{P}-31$; ésta fue una macromolécula de $90000 \mathrm{Da}$, su naturaleza se determinó como la de una glicoproteína termolábil, con amplio espectro de actividad antimicrobiana. Riquelme et al. (1996) aisla- ron una cepa de Alteromonas haloplanktis con actividad inhibitoria contra vibrios patogénicos, cuya naturaleza se sugiere como un compuesto proteinaceo.

En el presente trabajo se ha caracterizado parcialmente la naturaleza molecular proteinacea de una sustancia inhibidora semipurificada procedente de una especie de Alteromonas sp. cepa N22.C. La actividad inhibitoria de amplio espectro encontrada principalmente en el sobrenadante denota una vez más el origen extracelular de la sustancia antibacteriana; tales resultados son concordantes con los trabajos de Barja et al. (1989) y Riquelme et al. (1996), quienes a su vez consideran que las sustancias inhibitorias son metabolitos secundarios por excelencia, y por lo tanto se secretan extracelularmente. Por otro lado, en esta ocasión también se demostró la actividad inhibitoria aunque moderada en el extracto crudo intracelular (fracción insoluble). Al respecto, trabajos previos realizados por León (1996) mostraron resultados similares, considerando finalmente que pudo haber sido por el efecto residual de la sustancia inhibitoria que se conserva en el espacio periplásmico de las células bacterianas.

Debido a que la sustancia inhibitoria, sólo fue parcialmente fraccionada con concentraciones crecientes de sulfato de amonio hasta una saturación de $70 \%$, se deduce que tiene naturaleza proteinacea. Estos mismos resultados son reportados por Riquelme et al. (1996) en bacterias marinas aisladas de Argopecten purpuratus. Según los ensayos en PAGE-SDS la sustancia inhibitoria reveló tener una masa molecular de $34000 \pm 4000 \mathrm{Da}$, la cual se refleja como una banda ancha y difusa de proteína (2-3 mm) comprendidas entre los marcadores de 45000 y 29000 Da (Figuras 2, 3 y 4 ). Estos resultados difieren de los obtenidos por Ballester et al. (1977) y Barja et al. (1989), quienes determinaron en cepas marinas de Alteromonas sustancias inhibitorias de naturaleza glicoproteica de alto peso molecular $(90000$ Da). En el presente trabajo, se descartó la pre- 
sencia de residuos de azúcares asociadas a la sustancia inhibitoria de la cepa N22.C (Figura 5). Trabajos previos de caracterización con la cepa N22 (León y Tapia, 1999) revelaron también que la sustancia inhibitoria en estudio es termosensible a los $90^{\circ} \mathrm{C}$ en 45 minutos y se mantiene estable dentro de un amplio rango de pH (3 a 9). Asimismo, la actividad antibiótica de la sustancia semipurificada es comparativamente equivalente a $30 \mathrm{ppm}$ de oxitetraciclina en pruebas de antibiosis frente a Vibrio anguillarum NCMB 2133.

La sustancia inhibidora secretada por Alteromonas sp. cepa N22.C mostró su mayor actividad antagónica en la fase estacionaria y con ello, adopta el comportamiento de un metabolito secundario. Esta característica junto con la naturaleza proteinacea y actividad antibacteriana de amplio espectro son concordantes con los resultados obtenidos por otros investigadores como Lemos et al. (1985), Dopazo et al. (1988) y Riquelme et al. (1996) en otros aislados marinos del género Alteromonas.

En los últimos 15 años, las investigaciones sobre los metabolitos de bacterias marinas han permitido dilucidar la naturaleza molecular de muchas de estas sustancias. Tal es así, que un vibrio marino (C33), aislado de Argopecten purpuratus es productora de una sustancia bactericida cuya fracción activa fue caracterizada como un eter hidroxi alifático (Jonquera et al. 2000). Por otro lado, una bacteria marina sindicada como Pseudoalteromonas phenolica sp. nov. O-BC $30^{\mathrm{T}}$ fue señalada como productora de compuestos químicos que corresponde a 3,32 ,5,52 -tetrabromo-2,22 -bifenildiol (Isnansetyo \& Kamei, 2003) y otra bacteria identificada como Pseudomonas sp. AMSN es productora de 2,4-diacetil floro glucinol (DAPG) (Isnansetyo et al. 2003). Estos avances significan un reto para el presente trabajo, ya que en el futuro serán necesarios estudios que implican el uso de nuevas técnicas en el estudio de bacterias marinas y sus metabolitos.

\section{Literatura citada.}

Abraham TJ. 2004. Antibacterial marine bacterium deter luminous vibriosis in shrimp larvae. NAGA, World Fish Center Quarterly. 27 (3 \& 4) JulDec: 28-31

Andersen RJ, Wolfe MS, \& Faulker DJ. 1974. Autotoxic antibiotic production by a marine Chromobacterium. Mar. Biol. 27:281-85.

Austin, B., Stuckey LF, Bertson PAW, Effendi I, and Griffith DRW, 1995. A probiotic strain of Vibrio alginoyticus effective in reducing diseases caused by Aeromonas salmonicida, Vibrio anguillarum and Vibrio ordalii. Journal of Fish Diseases, 18:93-96

Ballester M, Ballester JM, \& Belaich JP. 1977. Isolation and characterization of a high molecular weigth antibiotic produced by a marine bacterium. Microb. Ecol. 3: 289-303

Barja JL, Lemos M and Toranzo AE. 1989. Purification and characterization of an antibacterial substance produced by a marine Alteromonas species. Antimicrob. Agents and Chemotheraphy. 33(10): 1673-1679.

Baumann P. \& Baumann L. 1984. Genus Alteromonas, pp 343. In: N. R. Krieg, and J. G. Holt (ed.), Bergey's Manual of Systematic Bacteriology. Vol. 1 Willians \& Wilkins, Baltimore.

Bernard P \& Pettazzi G. 1977. Purification partielle de deux antibiotiques produits par une bacteria marine appartemant un genre Alteromonas. Rev. Int. Oceanhr. Méd. 45-46:59-70

Bhunia AK, Johnson MC \& Ray B. 1988. Purification, characterization and antimicrobial spectrum of a bacteriocin produced by Pediococcus acidilactici. J. Appl. Bacteriol. 65:261-268

BioScience. 1996. Marine Biotechnology Special Issue, 46 Bradley SD. 1995. New Dimensions in Natural Products Research: Cultured Marine Microorganisms, Curr. Opin. Biotech. 6: 284-290

Brown RE, Jarvis KL \& Hyland KJ. 1989. Protein measurement using bicinchoninic acid: Elimination of interfering substance. Anal. Biochem. 180: 136-39

Burkholder PR, Pfister RM, \& Leitz FP. 1966. Production of a pyrrole antibiotic by a marine bacterium. Appl Microbiol. 14(4): 649-653

De Freitas MJ \& Fredrickson AG. 1978. Inhibition as a factor in the maintenance of microbial ecosystems. J. Gen. Microbiol. 106: 307-320

Dogget RG. 1968. New anti- Pseudomonas agent isolated from a marine Vibrio J. Bacterial. 95: 1972-73.

Dopazo CP, Lemos ML, Lodeiros C, Bolinches JJ, Barja JL \& Toranzo AE. 1988. Inhibitory activity of antibiotic producing marine bacteria against fish pathogens. J. Appl. Bacteriol. 65(2):97-101. 
Fenical W \& Jensen PR. 1993. Marine microorganisms: a new biomedical resource, pp 419-75 In: Attaway DH, Zaborsky OR. eds. Pharmaceutical and bioactive natural products. New York: Plenum 500 pp.

Gatesoupe FJ. 1999. Review: The use of probiotics in aquaculture. Aquaculture 180: 147-165.

Gauthier MJ. 1970. Substances antibacteriennes produites par les bacteries marines. II, Lipopolysaccharides antibiotiques produites par certains germes marins appartenant aux genres Pseudomonas et Chromobacterium. Rev. Int. Oceanog. Méd. 17: 23-45.

Gauthier MJ. 1976a. Alteromonas rubra sp. nov., a new marine antibiotic-producing bacterium. Int. J. Syst. Bacteriol. 26: 459-66.

Gauthier MJ \& Flatau GN. 1976. Antibacterial activity of marine violet-pigmented Alteromonas with special reference to the production of brominated compounds. Can. J. Microbiol. 22: 1612-19.

Isnansetyo A \& Kamei Y. 2003. MC21-A, a bactericidal antibiotic produced by a new marine bacterium, Pseudoalteromonas phenolica sp. nov. O$\mathrm{BC} 0^{\mathrm{T}}$, against Methicillin-resistant Staphylococcus aureus. Antimicrob Agents Chemother. 47(2): 480-488.

Isnansetyo A, Cui L, Hiramatsu K and kamei Y. 2003. Antibacterial activity of 2,4diacetylphloroglucinol (DAPG) produced by Pseudomonas sp. AMSN isolated from a marine alga, against vancomycin resistant Staphylococcus aureus (VRSA). Int. J. Antimicrob. Agents. 22:545-7.

Jayanth K; Jeyasekaran G; Jeya Shakila R. 2002. Isolation of marine bacteria antagonistic to human pathogens. Indian J. Marin. Sc. 31(1) : 39-44.

Jonquera MA, Riquelme CE, Loyola LA \& Muñoz LF. 2000. Production of bactericidal substances by a marine vibrio isolated from cultures of the scallop Argopecten purpuratus, Aquaculture International. 7(6): 433-448

Keen JH. 1966. Preparation and chemical properties of colicin 1. Can. J. Microbiol. 12: 425-26.
Kelecom A. 2002. Secondary metabolites from marine microorganisms. An Acad Bras Cienc. 74(1): 151-70.

Laemmli UK. 1970. Cleavaje of structural proteins during the assembly of the heat of bacteriophage T4. Nature (London) 227: 680-685.

Lemos ML, Toranzo AE \& Barja JL. 1985. Antibiotic activity of epiphytic bacteria isolated from intertidal sea-weeds. Microb. Ecol. 11: 149-63.

León J. 1996. Cepas nativas del bacterioneuston marino con actividad antagónica frente a bacterias ictiopatógenas. Caracterización preliminar de sustancias inhibidoras. Tesis para optar el grado de Magíster en Ciencias Microbiológicas. Universidad Católica de Valparaíso. Chile.

León J, Tapia G. 1999. Caracterización parcial y espectro antimicrobiano de sustancias inhibitorias producidas por Alteromonas marinas. Rev. Perú. Biol. 6(1): 94-103

Lodeiros CJM, Fernández E, Vélez A y Bastardo J. 1988. Producción de antibióticos por bacterias marinas y su utilización en acuicultura. Bol. Inst. Oceanogr. Venezuela, Univ. Oriente 27(1 y 2): 63-69.

Naclerio G, Ricca E, Sacco M, \& De Felice M. 1993. Antimicrobial activity of a newley identified bacteriocin of Bacillus cereus. Appl. Environ. Microbiol. 59: 4313-16

Riquelme C, Hayashida G, Araya R, Uchida A, Santomi M \& Ishida Y. 1996. Isolation of a native bacterial strain from the scallop Argopecten purpuratus with inhibitory effects against pathogenic vibrios. J. Shellfish Research 15: 369-374

Rosenfeld WD and Zobell CE. 1947. Antibiotic production by marine microorganisms. J. Bacteriol. 54: 393-398.

Sambrook J, Fritsch EF \& Maniatis T. 1989. Molecular cloning: A laboratory manual pp. 18.47-18.58 Cold Spring Harbor, NY.

Vignolo GM, Suriani F, Aída P. De Ruíz Holgado \& Oliver G. 1993. Antibacterial activity of Lactobacillus strains isolated from dry fermented sausages. J. Appl. Bacteriol. 75: 344-349. 